\title{
Manicômio Judiciário: é Possível ao Louco-Criminoso resistir?
}

Judiciary Mental Hospital: is it Possible for the Mentally ill Offenders to resist?

Manicomio Judiciario: es Posible al Loco-Criminal resistirse?

\section{Elza Ibrahim}

Professora adjunta da Universidade Veiga de Almeida. Mestra em Psicologia Clínica pela

Pontifícia Universidade Católica do Rio de Janeiro (PUC/RJ).

Junia de Vilhena

Professora do Programa de Pós-Graduação em

Psicologia Clínica da Pontifícia Universidade Católica do Rio de Janeiro (PUC-Rio).

http://dx.doi.org/10.1590 / 1982 - 370001542013
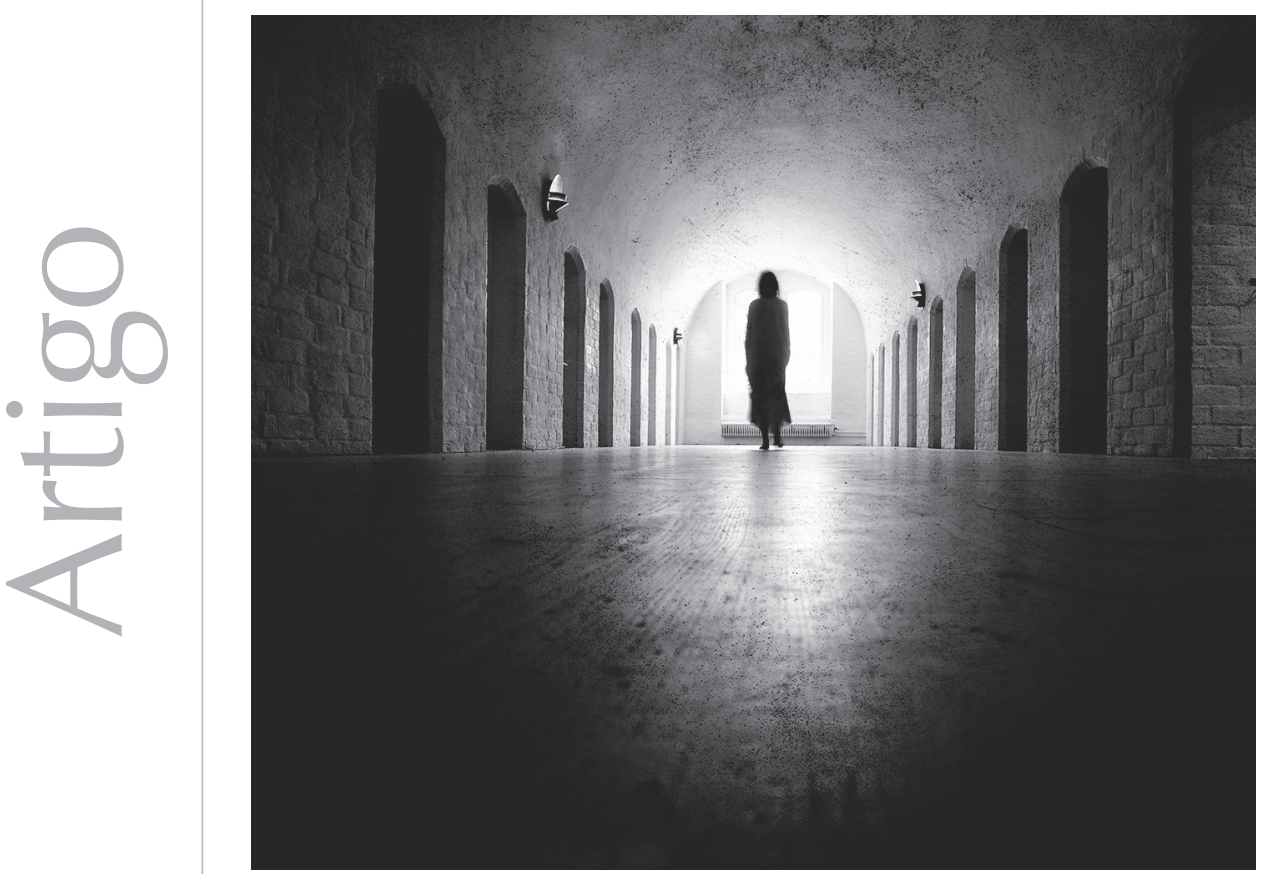
Resumo: O artigo aborda a questão da resistência problematizada por Michel Foucault e analisa as condições de possibilidade, tanto do chamado louco-criminoso, internado em instituição psiquiátrica-penal, quanto do profissional psi em poder resistir ao instituído, àquilo que está posto e determinado. Para tal, ancoramo-nos no pensamento filosófico foucaultiano e na capacidade criativa do sujeito em inventar o cotidiano por meio de novas maneiras de fazer que subvertem a ordem dominante, destacadas por Michel de Certeau. Nosso objetivo é apresentar a visão desses dois autores no que tange à questão da resistência e às estratégias em driblar a cronicidade do instituído e, assim, pensar sobre a atuação do operador de saúde no cotidiano de sua prática no interior das instituições totais.

Palavras-chave: Institucionalização. Psiquiatria forense. Resistência. Maneiras de fazer.

Abstract: The paper approaches the issue of resistance problematized by Michel Foucault and it analyzes the possibility conditions, both of the so-called mentally ill offenders, inpatient of judicial psychiatric institution and of the psychiatry professional in been able to resist the instituted, that which is put and set. To that end, we anchored in the Foucault's philosophical thought and in the subject's creative capability to invent everyday life through new ways of doing that subvert the dominant order, highlighted by Michel de Certeau. Our aim is to present the view of those two authors regarding the issue of resistance and the strategies to dribble the chronicity of the instituted and, thus, to think on the health operator's performance in his everyday practice inside total institutions.

Keywords: Institutionalization. Forensic psychiatry. Resistance. Ways of doing.

Resumen: El artículo aborda la cuestión de la resistencia problematizada por Michel Foucault y analiza las condiciones de posibilidad, tanto del Ilamado loco-criminal, internado en institución psiquiátrica-penal, como la del profesional psi en poder resistir al instituido, a aquello que está impuesto y determinado. Para tal, nos basamos en el pensamiento filosófico foucaultiano y en la capacidad creativa del sujeto en inventar el cotidiano a través de nuevas maneras de actuar que subvierten el orden dominante, destacadas por Michel de Certeau. Nuestro objetivo es presentar la visión de esos dos autores en lo que atañe a la cuestión de la resistencia y a las estrategias en driblar la cronicidad del instituido y, así, pensar sobre la actuación del operador de salud en el cotidiano de su práctica en el interior de las instituciones totales.

Palabras-clave: Institucionalización. Psiquiatria forense. Resistencia. Maneras de actuar.

Se é verdade que por toda a parte se estende e se precisa a rede de vigilância, mais urgente ainda é descobrir como é que uma sociedade inteira não se reduz a ela: "que procedimentos populares (também 'minúsculos`e cotidianos) jogam com os mecanismos da disciplina e não se conformam com ela a não ser para alterá-los?" (Certeau, 2005, p. 41. Grifo nosso).

Ao refletirmos sobre as condições de possibilidade do sujeito, encarcerado ou não, em procurar transformar aquilo que lhe é imposto, tanto pelas determinações sociais quanto pelas institucionais, constatamos os infinitos mecanismos por eles utilizados com o intuito de, não somente inventar novas maneiras de viver, mas também de criar formas de resistência a esse instituído. No caso do sujeito aprisionado, tanto nas prisões como nas instituições psiquiátrico-penais, as possibilidades de resistir àquilo previamente estabelecido tornam-se menos prováveis, mas não de todo impossíveis. Em se tratando do sujeito livre e comum, 
ocupante do espaço cotidiano das cidades, essas alternativas parecem ser mais factíveis.

Segundo Carlos Bernardo Vainer (1998), a cidade - enquanto invenção humana -, recusa a naturalização de qualquer espécie: a segregação e a intolerância ao diferente são processos sociais historicamente instituídos e, destarte, historicamente superáveis. Contudo, ainda que superáveis, observa-se que "a cidade tolera a heterogeneidade por sua utilidade" (Vainer, 1998, p. 35), isto é, a tolerância que se tem do outro é, na verdade, certa indiferença dirigida a ele. Simmel (1973) sustenta que a disposição à tolerância funda-se no desconhecimento da diferença. Afastamos tudo aquilo que parece diferente de nós mesmos.

Vivemos, pois, em um paradoxo, pois, justamente, por constituir-se de um núcleo de indivíduos socialmente heterogêneos, a cidade deveria ser o lugar de encontro das diferenças. Entretanto, o que se observa são os sentimentos de desconfiança e de medo com relação a essas "diferenças". O homem se protege do outro diferente de si e, a cada dia, vai se "acostumando com o fechamento paulatino dos espaços de convivência pelas grades" (ViIhena, 2005, p. 20). Muros e cercas tornamse fundamentais não só por razões de segurança, mas, principalmente, de segregação. Faz-se mister isolar-se o diferente, o outro, o perigoso. É necessário nos manter resguardados em espaços internos por precaução e por medo do que imaginamos ser o "diferente" vindo de fora. Vilhena (2005, p. 20) constata que "temos medo de andar pelas ruas, pelas praças, pelas avenidas, como se do aberto, do público, do ágora, pudessem surgir os demônios das 'classes perigosas' (...)".

Poderíamos afirmar que, dentre esses demônios das classes perigosas, estaria incluído o sujeito encarcerado, seja nas prisões, como nos manicômios. Será esse sujeito, aprisionado ou livre, capaz de desenvolver maneiras próprias de sobreviver às condições impostas pela intransigência e pela opressão da sociedade contemporânea? Será possível ao homem recusar o conformismo e a submissão ao já constituído e naturalizado inventando e criando, por outro lado, novas formas de fazer e de viver?

Nesse contexto, dois autores se fazem indispensáveis para enriquecer a nossa problematização. Michel de Certeau é um deles. De acordo com o autor (1998), a sociedade contemporânea, ainda que mantida sob as redes de controle e de "vigilância" generalizada, não se reduz e nem se rende a elas. Ao contrário, o sujeito se utiliza de procedimentos populares minúsculos e cotidianos e joga com os mecanismos de controle e de disciplina a fim de alterá-los, criando maneiras de fazer que se reapropriam do espaço organizado pelos métodos tradicionais de organização social produzindo, em contrapartida, uma nova ordenação sócio-política própria. É como se o sujeito reinventasse seu cotidiano, graças a jogos e práticas inventivas, tornando-se o narrador mesmo de seu discurso. Dito de outra maneira, seria possível ao indivíduo desfazer o jogo do outro por meio de estratégias de combate nas quais se verifica "uma arte dos golpes, dos lances, um prazer em alterar as regras de espaço opressor" (Certeau, 1998, p. 79).

Seguindo o mesmo viés, Michel Foucault (1979a) aponta para a necessidade de se criar novas maneiras de interpretação do sistema de regras - este, no mais das vezes, sem nenhuma significação essencial -, estabelecendo novas direções, produzindo novos jogos e, enfim, fabricando novas regras. Para ele, "o grande jogo da história será de quem se apoderar das regras (...), e voltá-las contra aqueles que as tinham imposto" (p. 25). O autor aponta para a indispensabilidade de um movimento de resistência inventiva, pro- 
dutiva, tal como sugere Certeau (1998) ao problematizar a questão das táticas e estratégias utilizadas para a reinvenção do cotidiano. Por estratégia, o autor entende o drible que mantém as regras do jogo, mas que, ao mesmo tempo, escapa. Por tática, compreendem-se as linhas de fuga que rompem com a lógica, tal qual a esquiva no jogo da capoeira.

É, portanto, sobre a necessidade imperiosa de se resistir ao instituído, ao instaurado e, porque não, àquilo que se encontra secularmente naturalizado, que se ocupa este artigo. Pretendemos problematizar a questão das condições de possibilidade, especialmente dos operadores da saúde, em reconhecer como primordial e imprescindível a produção de uma atitude de resistência àquilo que vem sendo, ao longo dos tempos, estabelecido como natural, como aceitável e, assim, excluindo qualquer outra forma de pensar ou de atuar. Acreditamos na premência de ações concretas que possam argumentar e combater a tese defendida, sobretudo pelas instituições psiquiátrico-penais, de que as normas vigentes não podem ser sequer questionadas. Acreditamos ser possível não somente questioná-las como, mormente, reinventá-las. Parafraseando Michel de Certeau, consideramos fundamental a criação de novas práticas e de novas estratégias que possam escapar, como em um drible, aos jogos cronificados do instituído.

\section{As descontinuidades da história: recriando o cotidiano}

Michel de Certeau e Michel Foucault foram historiadores contemporâneos e guardavam admiração recíproca. Ambos franceses, nascidos respectivamente em 1925 e 1926 e falecidos prematuramente - Certeau aos 61 anos e Foucault aos 58 - em um intervalo de apenas dois anos de diferença (1986 e 1984).
Os "dois Michel" preocupavam-se em desnaturalizar aquilo que se apresentava como definitivo, predeterminado, evidente e imutável. Ambos acreditavam na possibilidade do sujeito em criar e recriar o seu cotidiano.

Certeau, ao longo de sua obra, contribuiu sobremaneira para o entendimento a respeito da capacidade de criatividade das pessoas comuns em driblar o instituído, em encontrar "maneiras de fazer" que subvertem a ordem dominante, em não se conformarem com o que lhes é imposto, utilizando, para isso, as práticas de invenção do cotidiano (Certau, 1998). Em seu $A$ invenção do cotidiano, o autor problematiza a arte de viver a sociedade de consumo no que diz respeito aos modelos de ação característicos dos consumidores. Seguindo os seus ensinamentos - de que podemos criar sobre o já criado -, apropriamonos dessa ideia para pensar de que maneira a sua teoria poderia ser também utilizada com relação aos modos de subjetivação e de resistência do sujeito internado em manicômios judiciários.

Passamos a nos indagar sobre essa questão ao perceber a sensibilidade de Michel de Certeau em acreditar na força do indivíduo para se apropriar e alterar, por meio de pequenos golpes e astúcias, o modo de viver na sociedade contemporânea. De acordo com o autor, o homem comum inventa o cotidiano graças às táticas de resistência, às artes de fazer, alterando os objetos e suas regras, reapropriando-se do espaço mesmo e, finalmente, redesenhando-o de sua maneira.

Acreditamos, assim, estar o sujeito em constante transformação, recriando-se a cada embate com as circunstâncias que se apresentam. Em seu artigo Tornar-se quem se é, Sílvia Pimenta Velloso Rocha (2006) reflete que a cada um desses embates, o sujeito vai se constituindo como em uma "reinvenção de caráter sempre aberto, provisório, con- 
tingente" (p. 270). A autora traz, de maneira bastante significativa, a metáfora da água como imagem de transformação, dada a sua capacidade - pela maleabilidade - de assumir uma infinidade de formas diferentes, modificando-se a cada novo relevo que se introduz. Não se trata de entender o tornar-se quem se é como algo natural, como algo já existente no sujeito. Nem tampouco como um projeto a ser seguido com o propósito de se dirigir a vida em busca de uma essência, de um eu interior. Muito ao contrário, trata-se não de um processo transcendente, mas, sim, imanente no qual a vida é a trajetória aonde se vai - continua e incessantemente - tornando-se quem se é.

Com efeito, não se rejeita a ideia de que haja algo de interioridade no sujeito. Mas essa interioridade não deve ser entendida como uma essência, como algo imutável, inato ou, como já o dissemos, que já estava lá, mas algo que se modifica a cada tempo. Não se trata de pensar o homem como alguém que traz consigo uma essência ou uma origem que the marca e lhe confere um destino aprioristicamente. Essa interioridade do homem tem uma procedência externa e esse algo externo é construído em uma prática, em constante processo de produção e de invenção. Entretanto, a essa visão naturalista, vincula-se a noção de verdade que visa a buscar, objetivamente, quem é esse sujeito e como ele se estabelece em correspondência com a realidade. Nessa visão naturalista, o sujeito é, tão somente, fruto de uma essência, de uma origem que o marca definitiva e decididamente como alguém que não poderá modificar o rumo de sua história.

Contudo, é outra a nossa visão. Pensamos a subjetividade como um modo de existência, como processo indissociável da ideia de produção. A subjetividade é, portanto, processo de produção: o eu está em constante transformação e o homem se constitui pela ação das circunstâncias, pelo encontro com a alteridade, pela forma como ele assimila as experiências na relação com o outro.

Isso nos leva a pensar, trazendo à tona o ponto de vista foucaultiano, que a cada transformação novos pontos de vista se inserem, instaurando-se, assim, novas verdades. Foucault (2004) nos fala de múltiplas verdades: para ele, não existe uma verdade absoluta, universal, mas tão somente jogos de verdade articulados a estratégias de saber/poder que dizem o que é falso e o que é verdadeiro. Interessa a ele o enfrentamento analítico do presente, o olhar crítico aos jogos de verdade que fixam determinadas regras e as adotam como incontestáveis. Tais verdades tornamse absolutas e reinam incólumes no campo mesmo do instituído, impregnando de certezas as mentes - tantas vezes entregues à passividade e à obediência disciplinar - dos operadores da saúde em seu exercício no interior dos manicômios judiciários. Não é difícil constatar a sujeição às normas institucionais sem, ao menos, questioná-las.

Um exemplo claro e recorrente pode ser observado na prática mesma dos dispositivos jurídico-psiquiátricos utilizados tanto pelo saber médico, quanto pelo saber da Psicologia. Esses dispositivos gozam de certa regalia, pois "comportam presunções estatutárias de verdade e de poder que lhe são inerentes, em função dos que as enunciam. (...) são uma espécie de supralegalidade de enunciados na produção da verdade judiciária" (Foucault, 2001, p. 14).

Segundo Foucault, estes discursos presentes nos laudos do século XIX, imbricados no cruzamento da instituição jurídica e do saber médico, têm um caráter muito particular. Em primeiro lugar, porque eles têm o poder de estabelecer uma decisão judicial com respeito à liberdade ou à detenção de um homem. Ao mesmo tempo, são discursos que 
detém tal poder por, justamente, apresentarem-se como discursos de verdade, por serem discursos dotados de um estatuto científico e formulados, de modo exclusivo, por pessoas qualificadas para dizê-los (Fonseca, 2002, p. 74). Assim, o sujeito é colocado e submetido, à sua revelia, àquele que, no momento, detém determinado saber/poder, conferindo a este sujeito um lugar de não sujeito, obstruindo e dificultando a sua possibilidade de ação.

Pensamos que, da mesma forma que esse sujeito considerado inimputável se sente obstaculizado em resistir às normatizações impostas no campo do instituído, também ao psicólogo essa tarefa torna-se, por vezes, uma tarefa infausta. Na maior parte do tempo, ele se vê aprisionado nos interstícios dos jogos de poder e dos jogos de verdade, tão bem revelados por Foucault (2004), deixando-se enredar por seus discursos e, assim, acaba por comprometer-se com a manutenção mesma da ordem vigente. É comum encontrarmos profissionais que apresentam um discurso libertador, mas, geralmente esse discurso mostra-se desconectado de sua prática.

Afinal, qual a implicação do profissional psi nessa trama? A partir de que princípios ele se adapta ou não às formas de exclusão, marginalização e de controle que esses dispositivos produzem? Em que medida ele se naturaliza ou não com essas tecnologias? Como ele resiste - ou não - aos exercícios de poder e a certas normatizações?

De acordo com a reflexão trazida por Foucault (1979c), "vivemos em uma sociedade que em grande parte marcha 'ao compasso da verdade', ou seja, produz e faz circular discursos que funcionam como verdade, que passam por tal e que detêm por este motivo poderes específicos" (p. 231).

Mas, voltemos a Michel de Certeau. Segundo
Roger Chartier (1996), o autor não gostava muito de se autodefinir, nem tampouco de se encerrar em uma categoria acadêmica. Certeau preferia considerar-se um historiador, um viajante. Toda a sua obra centralizou-se na análise das práticas mediante as quais o sujeito se apropria, de sua maneira, das normas e dos lugares que lhe são impostos ou até mesmo subverte as regras comuns para criar práticas inéditas. De acordo com Chartier (1996), "las práticas del lenguaje de la mística son emblemáticas de esas "artes de hacer" o "hacer com" que desvían los materiales de que se apoderan" (pp. 70-71).

Certeau (1998) acredita na criatividade oculta em uma rede de astúcias sutis e, muitas vezes, silenciosas, que vão criando possibilidades ao sujeito de inventar uma maneira própria de caminhar pelas vielas do cotidiano, pelos labirintos das práticas instituídas. Não importa qual seja este instituído: um produto a ser consumido ou um modelo institucional a ser seguido. Essa maneira de ser e de se situar na vida caminha na contramão, como um movimento de resistência àquilo que está posto, àquilo que está naturalizado. Além do autor se ocupar com os modelos de ação característicos dos sujeitos que, por meio das artes de fazer, inventam o cotidiano, também ele se mostrou um estudioso na análise sobre as questões institucionais, procurando pensar o estranho com o qual nos deparamos na vida coletiva.

Outra autora contribui sobremaneira para a análise do estranho no espaço social. Tratase de Giovanna Ferreira Dealtry (2007), que entende que o olhar suspeito e preconceituoso que a metrópole lança sobre o sujeito no espaço urbano se deve ao fato desta não conseguir decifrá-lo. E por não consegui-lo, o homem se torna suspeito e ameaçador e passa a ser visto como o louco, o marginal, enfim, o estranho. A rua torna-se o espaço 
do perigo, do imprevisível, e o sujeito que a ocupa torna-se uma ameaça em potencial. Assim, para se proteger da ameaça, a sociedade tenta controlar esse elemento suspeito, classificando-o.

O ímpeto do individuo em querer decifrar o indecifrável, em controlar aquilo que desconhece ou aquilo que the parece diferente de si próprio, data dos primórdios. Foucault (2001) ressalta que esse comportamento diz respeito à necessidade do homem de multiplicar os efeitos do poder a partir do acúmulo da observação e do saber. Observa-se o indivíduo para depois classifica-lo e, por fim, controlá-lo. Trata-se de uma rede previsível e anunciada.

Contudo, o filósofo-historiador, semelhante à Certeau, pensa o sujeito e a história em termos de descontinuidade, de singularidade, com temporalidades distintas. Assim, podemos constatar que a perspectiva foucaultiana usaria a história para romper com o presente, para desestabilizá-lo, para desnaturalizá-lo. Tratase de uma perspectiva desconstrutivista, pronta para "rir das solenidades da origem" (Foucault, 1979a, p. 18). Crítico do viés historicista, não no sentido de negar a história, mas no sentido de recusar o conceito de história atrelado à ideia de origem, à ideia de uma verdade única e primeira, o autor reflete:

A história (...) não tem por fim reencontrar as raízes de nossa identidade, mas ao contrario, se obstinar em dissipá-la; ela não pretende demarcar o território único de onde viemos (...); ela pretende fazer aparecer todas as descontinuidades que nos atravessam. (p. 35)

Para ele, o sujeito é todo tempo atravessado, não só pelas contingências e pelo aspecto fortuito da vida, mas também pelas regras e exigências que se nos impõem por meio dos jogos de saber/poder que nos constitui. Sim, sob o ponto de vista foucaultiano, o sujeito é formado a partir de relações de poder. Entretanto, Foucault nos traz uma valiosa con- tribuição ao ampliar o conceito de poder: ele é entendido como uma relação de forças, na qual se afeta e se é afetado, implicando uma estratégia de luta e de resistência: "o poder não existe; existem sim, práticas ou relações de poder" (Machado, 1979, p. 14). É como se na aparente assimetria no campo de poder, houvesse uma simetria de base, em que ambos os lados são afetados. Assim, poderíamos dizer que, a despeito do poder instituído, há algo que acontece nos interstícios das relações; e este algo seria a resistência. Parece, portanto, que a relação de poder e as forças que resistem não podem ser separadas uma da outra.

Com efeito, não existe o sujeito, mas um sujeito em constante transformação, reinventando-se sempre, criando novas saídas, construindo novos percursos. A história, segundo Gilles Deleuze (1992), circunscreve e entremeia o sujeito sem, contudo, fixar ou prescrever quem ele é, mas aquilo de que está em vias de diferir. Para ambos os autores, tanto as astúcias dos consumidores, referidas por Certeau, como as estratégias de antidisciplinas, mencionadas por Foucault, surgem como resistência às imposições científicas e sociais.

Mas, retornemos àquele sujeito internado nos manicômios, na categoria de paciente inimputável que, segundo o Decreto-Lei no 7.209 de 11 de Julho de 1984 do Código Penal Brasileiro (Brasil, 1984), trata-se da pessoa que cometeu uma infração penal, porém, no momento do crime, era inteiramente incapaz de entender o caráter ilícito do fato ou de determinar-se de acordo com esse entendimento.

Abramos um parêntese para trazermos à lembrança a maneira como o doente mental - assim como todos aqueles que se diferenciavam das normas vigentes ou que apresentassem qualquer tipo de alteração - foram vistos e tratados ao longo dos tempos. No 
início do século XV, o louco, então denominado lunático, pecador, usufruía de relativa liberdade e era apoiado pela caridade alheia. Em algumas localidades da Europa, era comum deixar-se que o louco vagasse pelos campos, enquanto que, em outras sociedades europeias, ele convivia livremente junto aos mendigos, mágicos, libertinos, enfim, àqueles considerados como diferentes dos demais. Com o passar dos tempos - considerados marginais e improdutivos -, já não lhes era mais permitido compartilhar o espaço social. As cidades começam, então, a expulsá-los. Nessa lógica da exclusão, Foucault (2009) traz a imagem ficcional da Nau dos loucos, em que o sujeito fica a mercê da sua própria errância, preso em sua própria liberdade. Louco e desterritorializado, ele vagueia pelos mares até ser definitivamente excluído de todo e qualquer contato com o mundo.

Ironicamente - apesar da voz do louco anunciar a morte e o caos e, com isso, ser afastado do convívio dos demais cidadãos -, a loucura não era algo que se prendesse e sim algo que circulava (Fonseca, 2002). Ao expulsálo para longe de seus domínios, impediamno de circular pelas ruas, tornando-se, desse modo, um estorvo para a população. Embarcado, navegante de grandes mares e rios, era-lhe impossível escapar, pois "prisioneiro no meio da mais livre, da mais aberta das estradas: solidamente acorrentado à infinita encruzilhada" (Foucault, 2009 a, p. 12). O louco não se encontra, ainda, nesse momento, enclausurado: ele é, tão somente, aquele sujeito que fala sobre algo que o não louco se surpreende, que se inquieta, que não entende, mas, ao mesmo tempo, fascinado, quer se aproximar e ouvir. O louco é aquele que ainda não apresenta nenhuma ameaça. Trata-se da concepção trágica da loucura.

Contudo, já não basta mais afastar o louco ou deixá-lo errante, à sua própria sorte. As viagens a céu aberto nas estranhas e loucas barcaças vão dando lugar, pouco mais de um século depois, a sólidos locais fincados em terra firme: já não existe mais a nau; em seu lugar, aporta o hospital. Assim, "a loucura, cujas vozes a Renascença acaba de libertar, cuja violência, porém ela já dominou, vai ser reduzida ao silêncio pela era clássica (...)" (Foucault, 2009 a, p. 45). Destarte, aqueles passageiros anônimos são despejados pelas naus e, com o tempo, algumas cidades surgem como lugares de peregrinação. Criase, então, uma nova forma de assistência no que diz respeito à questão da loucura: o encarceramento dos insanos. O século XVII faz acontecer o "grande confinamento". Aí já não mais se ouve a voz do louco, mas tão somente o seu silêncio.

Com o surgimento da Criminologia em 1876, o médico cirurgião Cesare Lombroso começa a investigar o arquétipo do criminoso nato, por meio dos traços morfológicos, podendo assim antever os indivíduos que se voltariam para o crime. Desta feita, comparando as medidas do corpo humano, cientistas do século XIX chegaram à conclusão de que o negro era inferior ao branco por possuir um cérebro menor do que aquele. Com o decorrer da história, as pessoas já não eram definidas apenas pela cor da pele ou pelo ângulo facial. Começaram a surgir maneiras cada vez mais refinadas de classificação, que isolavam e estigmatizavam aqueles que não cumpriam o padrão preestabelecido pela sociedade de classes. A ciência, segundo Foucault (2009), passa a classificar o sujeito com fins de controle e segregação. Aqueles conotados como diferentes ocupavam um lugar à margem, à exclusão.

Vários são os autores que problematizaram a respeito do afastamento e da restrição aos "diferentes", daqueles que fogem à norma. Löic Wacquant (2001) aponta em direção aos guetos norte-americanos, que são vistos pelos de fora como o lugar do misterioso, 
do impenetrável. Aquele que o habita, não raro, é percebido como o estranho, o diferente, o perigoso. Freud (1919/1976) relaciona o termo estranho com o que é assustador, o que provoca medo e horror. Define-o como sendo aquilo que não é doméstico, com o não familiar. Entretanto, afirma também que o estranho é aquela categoria do assustador que remete ao que é conhecido, de velho e há muito familiar, mas algo que não se sabe abordar. Para o sociólogo José de Souza Martins (2002), a exclusão impede o sujeito a possibilidade de construir historicamente o seu próprio destino, a partir de sua própria vivência. Aquele considerado como sendo o estranho, o diferente, o louco, nada mais é do que o homem visivelmente descartado e secundarizado como pessoa.

Mas, retornemos àqueles considerados inimputáveis: de que maneira, então, esses pacientes - igualmente excluídos do grupo social - poderiam resistir ao que lhes é determinado?

As histórias são muitas e as manifestações de oposição também. Uma paciente do setor feminino se nega a ir a uma comemoração de aniversário, caso não possa usar vestes comuns, ao invés do uniforme exigido pelo regimento do hospital. De acordo com as normas do Manicômio Judiciário Heitor Carrilho - Hospital-Penal do Departamento Penitenciário do Rio de janeiro -, é proibido às pacientes femininas - mas não aos pacientes masculinos - vestirem-se com suas próprias roupas. Elas são obrigadas a se manter uniformizadas, ainda que nas comemorações e festividades quando, naturalmente, desejem vestir-se com roupa de festa. Certamente enriqueceria o nosso trabalho toda a discussão acerca das relações extremamente desiguais entre homens e mulheres, tratadas como normas inquestionáveis pelo MJ. Contudo, dado o escopo deste trabalho, optamos por não nos determos a esse ponto, apontando apenas por revelar a existência de tamanha disparidade com relação ao tratamento reservado às pacientes femininas.

A partir da situação acima relatada, poderíamos analisar a questão do poder sob dois ângulos distintos: entendendo-o da maneira tradicional, como aquele poder que impede o sujeito de exercer as suas próprias forças, produzindo-se, assim, um sujeito sujeitado. Nesse caso, teríamos o exemplo da escravidão e de algumas situações de tortura. Entretanto, ao falar de poder, Foucault se refere a algo que está sempre presente e que se exerce como uma multiplicidade de relações de forças. É como se o poder incitasse, estimulasse a paciente, não a reagir, mas sim, a resistir, quando esta se nega a comparecer à festa. $\mathrm{E}$ é dessa forma que o poder é visto como resistência:

(...) Não coloco uma substância da resistência face a uma substância do poder. Digo simplesmente: a partir do momento em que há uma relação de poder, há uma possibilidade de resistência. Jamais somos aprisionados pelo poder: podemos sempre modificar sua dominação em condições determinadas e segundo uma estratégia precisa (Foucault, 1979c, p. 241)

Nesse caso, não estaria a paciente manifestando a sua resistência com relação a essas normas, já que, para ela parecem isentas de significação?

Tanto Certeau quanto Foucault, ambos se rebelavam contra a idéia de se aceitar o cotidiano e o entendimento sobre a loucura como uma prática passiva, a mercê das imposições da psiquiatria, do mercado e dos jogos de saber/poder. Há sempre no sujeito a capacidade de resistir, ainda quando em uma relação de poder, um tenha todo o poder sobre o outro, ainda que essa relação de poder se mostre completamente desequilibrada, "um poder só pode se exercer 
sobre o outro à medida que ainda reste a esse último a possibilidade de se matar, de pular a janela, ou de matar o outro" (Foucault, 2004 , p. 277). Com isso, o autor pretende constatar que, nas relações de poder, há sempre possibilidade de resistência - seja ela de fuga, de táticas ou de estratégias que invertam a situação -, pois, caso não houvesse possibilidade de resistência, não haveria, tampouco, segundo o autor, forma alguma de relações de poder.

Para eles, tanto as astúcias dos consumidores (Certeau, 1998) como as estratégias de antidisciplinas (Foucault, 2010), surgem como resistência às imposições científicas e sociais. De acordo com esses autores, é preciso jogar-se com os acontecimentos para transformá-los em ocasiões, em momentos oportunos a fim de driblar as regras obsoletas dos jogos cronicamente ordenados. Ambos, mais uma vez, complementam-se em suas ricas e criativas problematizações.

O brilhante geógrafo Milton Santos (1997), ao discorrer sobre a geografia e outras disciplinas que estudam o território, argumenta que "o fenômeno humano é dinâmico e uma das formas de revelação desse dinamismo está, exatamente, na transformação qualitativa e quantitativa do espaço habitado" (p. 37). Em outras palavras, poderíamos constatar que, ao apropriar-se do espaço, o homem o humaniza. Questionamos se, desse modo, não estaria o sujeito encarcerado no interior das instituições totais como a paciente que se nega a participar da festa em trajes manicomiais -, tentando apropriar-se não somente de seu espaço como também procurando resistir ao que lhe é imposto? Não seriam essas "atitudes de indisciplina", esses "golpes no terreno da ordem estabelecida" (Certeau, 1998, p. 88) expressas pela paciente que poderiam levar a instituição mesma a repensar sobre o seu quadro de normas e regras? Não será necessário, em algumas situações, opor-se ao naturalizado, ao instituído, ao porque sempre foi assim?

\section{O sujeito psi: resistência ou normatização?}

Sabemos que, da mesma forma que ao inimputável faz-se difícil reagir às normas institucionais, também ao psicólogo ocorrem dificuldades semelhantes. Sem dúvida, de acordo com Michel Foucault, o papel dos profissionais de saúde está atrelado a um sistema de poder, funcionando como mais uma peça da engrenagem institucional. Indagamos, então, de que maneira o profissional psi e toda uma rede de práticas e instituições poderia contribuir para facilitar o surgimento e a criação de novos modos de subjetivação do sujeito encarcerado?

Esse lugar paradoxal leva o profissional psi tanto a utilizar intervenções normatizadoras e adaptativas quanto a produzir práticas que promovam a criação de novas aberturas e de transformação para outras subjetividades. Não se pode mais aceitar uma falsa neutralidade, como nos advertem Félix Guattari e Suely Rolnik em Cartogafias do Desejo (1990). O profissional de saúde não pode se deixar apaziguar nem deixar de se surpreender com aquilo que está posto, com a cronicidade do cotidiano. Ou ele se adapta às praticas e instrumentos teórico-práticos preestabelecidos e, dessa forma, identifica-se maciçamente com os valores institucionais, ou ele tenta desestabilizar esse lugar neutro e seguro implementado e sustentado pelo poder hegemônico, resistindo a ele por meio de uma bricolagem, "usando inúmeras e infinitesimais metamorfoses da lei, segundo seus interesses próprios e suas próprias regras" (Certeau, 1998, p. 40). Contudo, o que se encontra, em geral, é o especialista que desqualifica essas bricolagens e que se preocupa apenas em deter um suposto saber e o poder de falar uma suposta verdade. 
Não fosse o bastante, observa-se, além disso, uma prática viciosa e perversa de se falar pelo outro. Esse outro - o louco, o delinquente, o que protesta -, passa a ter nenhuma importância: o poder fica nas mãos de quem o detém. Aquele sequer é ouvido. Fala-se por ele. Fala-se sobre a loucura, fala-se sobre a delinquência, mas não se ouve aqueles considerados como tais.

Acompanhando Martins (2002), acreditamos na importância da participação do sujeito no processo mesmo de mudança, no reconhecimento como autor e transformador de sua própria história. Conhecendo a sua realidade, o sujeito tem acesso a uma identidade social, que o faz saber quem ele é e aonde quer chegar. Quando se impede o sujeito de participar da sua realidade, está-se negando a sua existência como ser humano. Martins (2002) denuncia o desencontro entre a maneira como as vítimas se situam com seus infortúnios dentro da sociedade e a forma como os profissionais acadêmicos ou de campo a percebem, de fora para dentro. Com frequência, trazem prontas as suas teorias, tentando encaixá-las em conceitos preestabelecidos.

Constata-se a importância de se tomar a realidade como base para a teoria e não o contrário. Não é a teoria que define os problemas do grupo social, e sim os problemas é que definem a sua teorização.

Deleuze, em uma conversa com Foucault (1979b), afirma que a "teoria é uma caixa de ferramentas que, por si só, não tem serventia. Ela só é útil se houver lugar onde ser utilizada" (p. 71). Nesse mesmo texto, Foucault nos alerta com brilhantismo sobre o lugar dos intelectuais que falam pelas massas e pensam saber delas mais do que elas próprias sabem. Articulando teoria e prática, o autor organizou o G.I.P. (Groupe d'Information sur les Prisons) no ano de 1971 em Paris, tendo entre seus signatários, Gilles Deleuze, Danielle Rancière e Jacques Donzelot. O G.I.P. foi um movimento de ação e de informação criado com o objetivo de passar a palavra aos presos e, ao mesmo tempo, de permitir a mobilização de intelectuais e profissionais envolvidos no sistema prisional francês. Não se tratava absolutamente de uma associação de intelectuais, mas, sim, de um grupo plural composto por detentos, ex-detentos e suas famílias; por magistrados, médicos e intelectuais - de um modo geral , todos eles envolvidos na mesma causa: criar condições para que os presos pudessem falar por si mesmos.

Assim, foi possível se constatar que as massas não precisam dos intelectuais para saber; elas sabem melhor que eles. E mais: elas sabem dizer o que sabem. Não obstante, Foucault (1979b) adverte que existe um sistema que obstaculiza esse saber, tentando vedálo, dirimi-lo.

Isso nos remete, com pesar, a atitudes tomadas por alguns intelectuais que tentam se apropriar de histórias e experiências de vida, tanto de grupos quanto de movimentos culturais, travestindo as suas singularidades em discursos sociológicos, psicológicos e afins. Não é incomum assistirmos o contar-se a história da favela sem se ouvir o favelado; discutir o problema do abuso de drogas sem se ouvir o usuário ou, ainda, de se problematizar as questões da loucura deixando de se ouvir o louco.

Contudo, os exemplos de atitudes distintas a essas têm sido mais frequentes. Podemos citar o RAP (Rythm and Poetry): a arte de contar histórias por meio da poesia. Trata-se de um dos cinco elementos que compõem o movimento hip-hop. Nele, o narrador, apropria-se de sua história mesma e insiste não só em falar e a interpretar a si próprio, como também a interpretar o mundo à sua volta, entrelaçando 
os fatos com a análise da subjetividade, resistindo a não se deixar ser contado por meio da VOz do outro. Esse movimento, assim como tantos outros, inscreve

na língua ordinária as astúcias, os deslocamentos, elipses, etc. que a razão científica eliminou dos discursos operatórios para constituir sentidos "próprios". (...) eles caracterizam uma arte de dizer popular, (...) um estilo de pensamento e de ação - modelos de práticas. (Certeau, 1998, pp. 85-86)

Reconhecer o outro, portanto, possibilita ao sujeito se apossar de sua própria história contribuindo, ele mesmo, para a formação de novas subjetividades. Isso nos faz lembrar a obra do grande cineasta Eduardo Coutinho (1997), que costuma ouvir as histórias dos homens comuns, retratados, principalmente nos documentários: Santa Marta: duas semanas no morro; Santo Forte; e Edifício Master, dentre tantos outros. Neles, Coutinho interage e confere a palavra a quem, de fato, pertence.

Outro documentarista, João Moreira Salles (Lund \& Salles, 1999), em seu documentário Notícias de uma guerra particular, não se preocupa em mostrar a polícia ou o dono do morro, mas a história comum dos trabaIhadores residentes em uma favela no Rio de Janeiro, da mesma forma como o rapper MV Bill (Athayde \& MV Bill, 2006), que ouviu os invisíveis falcões do tráfico. Entretanto, não é o que ocorre com aqueles que se encontram encerrados nas instituições totais, termo formulado por Goffman (1974): ao serem descritos e analisados por meio dos procedimentos psico-jurídicos, os pacientes são falados por meio da voz do especialista, que passa a ser o detentor da verdade sobre a história daqueles sujeitos, julgando saber deles mais do que eles próprios.

No texto Os intelectuais e o poder (1979), Deleuze dirige-se a Foucault dizendo que "a meu ver, você foi o primeiro a nos ensinar - tanto em seus livros quanto no domínio da prática - algo de fundamental: a indignidade de falar pelos outros" (p. 72). Complementando, o filósofo e pesquisador José Carlos Bruni (1989) em seu belo artigo, Foucault: o silêncio dos sujeitos, mostra como Michel Foucault tentou romper com as filosofias tradicionais do sujeito e, mormente, recusouse a dar voz ao silêncio desse sujeito.

Frente a tudo isto, várias inquietações surgem: como fazer as práticas de saúde não se tornarem simples repetição de modelos herméticos e universais? Como fazer surgir novos modos de invenção da vida, a despeito das forças hegemônicas que remam incessantemente para o lado oposto do oceano? Como vimos anteriormente, nossos dois autores se complementam no que diz respeito às possibilidades de produção de novos modos e maneiras de ser, por meio, segundo Certeau, do uso de táticas e estratégias, assim como a arte da capoeira: um jogo de inventividade artesanal, de esquivas, de dribles que são nada menos do que a capacidade de resistência, presente em todo e qualquer sujeito, conforme constata Foucault. Enquanto que para Michel de Certeau (1998), "o cotidiano se inventa com mil maneiras de caça não autorizada" (p. 38), para Michel Foucault (1979c), "jamais somos aprisionados pelo poder; podemos sempre modificar sua dominação em condições determinadas e segundo uma estratégia precisa" (p. 241).

É como se o poder estimulasse o sujeito a resistir. Sem dúvida, a resistência se define nas relações de poder, isto é, não se trata de uma capacidade inata que antecede a relação: a resistência ocorre na relação mesma. Para Foucault, a resistência pressupõe um sujeito ativo, capaz de dizer não. Com efeito, não estamos condenados ao poder: podemos resistir a ele, podemos criar linhas de fuga. 
(...) Cada vez mais coagido e sempre menos envolvido com esses enquadramentos, o indivíduo se destaca deles sem poder escaparIhes, e só lhe resta a astúcia no relacionamento com eles, "dar golpes", encontrar na megalópole eletrotecnicizada e informatizada a "arte" dos caçadores ou dos rurícolas antigos. (Certeau, 1998, p. 52)

\section{Considerações finais}

Certeau e Foucault nos mostram a necessidade de se problematizar o papel do profissional psi no que diz respeito à sua implicação e intervenção dentro do campo da saúde mental. Estamos nos referindo às práticas de resistência ao poder instituído, tanto por parte do sujeito internado como do próprio operador de saúde. Como já foi dito, ao criar o G.I.P. Foucault (2010) se ocupou por preferir, segundo ele próprio, "um trabalho efetivo à loquacidade universitária e aos rabiscos de livros. (...) uma ação política concreta em favor dos prisioneiros" (p. 291). Levando-se em consideração a presença, segundo Certeau, de relações de forças entre o fraco e o forte, pensamos que a ação de Foucault no G.I.P. se manisfesta como uma resistência que, desta vez, parte do pesquisador mesmo.

As invenções cotidianas representam as diferentes formas de os profissionais de saúde se adequarem, mas de não se conformarem com as estratégias presentes no campo institucional, criando recursos que promovam a reorganização e a recriação do cotidiano de suas práticas. Tais invenções vão, por outro lado, gerando novo saberes, doravante, saberes produzidos pelos próprios profissionais, viabilizando, assim, condições de possibilidade para que o próprio paciente possa resistir ao que lhe é imposto. Para elucidar, podemos citar o mesmo acontecimento mencionado. Vimos que a paciente se negara a comparecer ao evento, caso fosse obrigada a vestir suas vestes hospitalares. Essa regra institucional jamais fora discutida ou indagada. Ao longo de décadas, ela permanecia fixa, incólume. Indagaríamos, pois: não caberia ao operador da saúde, trabaIhando e conhecendo a engrenagem manicomial em seus meandros, questionar tal conjunto de regras que se impõem no campo institucional e que se eternizam como verdades absolutas? Não caberia se surpreender com tais postulados de verdade? Não caberia ao menos questionar, ao ouvir como resposta da instituição, de que era proibido usar vestes não hospitalares "porque sempre fora assim"?...

Pensamos que, tanto o operador da saúde como o paciente internado nos manicômios possam resistir - cada qual com suas diferentes "maneiras de fazer" - àquilo que é imposto e que se perpetua ao longo do tempo e da história das instituições totais.

Cremos que, ao estabelecermos linhas de fuga que possibilitem a ruptura dos padrões cronicamente institucionalizados, possamos criar relações estratégicas que ampliem e diversifiquem as possibilidades de inventar novos modos de relação consigo mesmo e com o outro.

Acreditamos que o profissional psi - e os demais trabalhadores na área de saúde - deve problematizar e tentar analisar como acontece o processo de sujeição, "o conjunto de obstáculos que antecedem à constituição dos sujeitos, (...) como, a partir de mecanismos sociais complexos que incidem sobre os corpos, foram-se dando historicamente mil formas de sujeição" (Bruni, 1989, p. 201), dentre elas, a do louco-criminoso. 


\section{Elza Ibrahim}

Professora adjunta da Universidade Veiga de Almeida. Mestra em Psicologia Clínica pela Pontifícia Universidade Católica do Rio de Janeiro (PUC/RJ).

\section{Junia de Vilhena}

Professora do Programa de Pós-Graduação em Psicologia Clínica da Pontifícia Universidade Católica do Rio de Janeiro (PUC-Rio). Coordenadora do Laboratório Interdisciplinar de Pesquisa e Intervenção Social - LIPIS da PUC-Rio. Pesquisadora da Associação Universitária de Pesquisa em Psicopatologia Fundamental. Pesquisadora correspondente do Centre de Recherches Psychanalyse et Médecine, CRPM-Pandora. Université Denis-Diderot Paris VII. Investigadora-Colaboradora do Instituto de Psicologia Cognitiva da Universidade de Coimbra.

\section{Endereço para envio de correspondência:}

Rua Humaitá 270 ap. 805 / Lagoa, Rio de Janeiro - RJ - Brasil. CEP: 22261-001. Tel.: (21) 25398597

E-mail: elzaibrahim@terra.com.br

E-mail: vilhena@puc-rio.br

Recebido em: 22/06/2013, 1a Reformulação 14/10/2013, Aprovado 16/10/2013. 


\section{Referências}

Athayde, C., \& Bill, M.V. (2006). Falcão: Meninos do tráfico. Rio de Janeiro: Objetiva.

Bruni, J. C. (1989). Foucault: O silêncio dos sujeitos. Revista Tempo Social, 1(1), 199-207.

Certeau, M. de (1998). A invenção do cotidiano 1: artes de fazer. Petrópolis, RJ: Vozes.

Chartier, R. (1996). Escribir las práticas. Buenos Aires: Manantial.

Coutinho, E. (1997). O cinema-documentário e a escuta sensível da alteridade. Projeto História, 15, 165-193.

Dealtry, G. F. (2007). Diante de janelas: fronteiras entre público e privado na (pós) modernidade. Revista Estudos e Pesquisas em Psicologia, 7(2), 188-197.

Brasil. (1984). Decreto-Lei $n^{o} 7210$ de 11 de Julho de 1984. Institui a Lei de Execução Penal. Brasília, DF. Recuperado de: www.planalto.gov.br/ccivil 03/leis/l7210.htm .

Deleuze, G. (1992). Conversações. São Paulo: Editora 34.

Fonseca, M. A. (2002). Michel Foucault e o Direito. São Paulo: Max Limonad.

Foucault, M. (1979a). Nietzsche, a genealogia e a história. In M. Foucault, Microfísica do poder (pp. 15-38). Rio de Janeiro: Graal.

Foucault, M. (1979b). Os intelectuais e o poder. In M. Foucault, Microfísica do poder (pp. 6978). Rio de Janeiro: Graal.

Foucault, M. (1979c). Não ao sexo rei. In M. Foucault, Microfísica do poder (pp. 229-242). Rio de Janeiro: Graal.

Foucault, M. (2001). Os anormais. São Paulo: Martins Fontes.

Foucault, M. (2004) A ética do cuidado de si como prática de liberdade. In M. Foucault, Ditos \& Escritos, V: ética, sexualidade, política (pp. 264-287). Rio de Janeiro: Forense Universitária.

Foucault, M. (2009). História da loucura. São Paulo: Perspectiva.
Foucault, M. (2010). O grande internamento. In M. Foucault, Ditos \& Escritos, I: problematização do sujeito: psicologia, psiquiatria e psicanálise (pp. 285-296). Rio de Janeiro: Forense Universitária.

Freud, S. (1976). O estranho. In Edição standard brasileira das obras psicológicas completas de Sigmund Freud (Vol. 17, pp. 275-314). Rio de Janeiro: Imago. (Trabalho original publicado em 1919)

Guattari, F., \& Rolnik, S. (1990). Cartografias do desejo. Rio de Janeiro: Vozes.

Goffman, E. (1974). Manicômios, prisões e conventos. São Paulo: Perspectiva.

Machado, R. (1979). Por uma genealogia do poder. In M. Foucault, Microfísica do poder (pp. VII- XXIII). Rio de Janeiro: Graal.

Martins, J. S. (2002). A sociedade vista do abismo: novos estudos sobre a exclusão, pobreza e classes sociais. Petrópolis, RJ: Vozes.

Rocha, S. P. V. (2006). Tornar-se quem se é: educação como formação, educação como transformação. In C. Feitosa (Org.), Nietzsche e os gregos. São Paulo: DP\&A.

Lund, K., \& Salles, J. M. (Produtores). (1999). Notícias de uma guerra particular. (Documentário). Rio de Janeiro.

Santos, M. (1997). Metamorfose do espaço habitado. São Paulo: Hucitec.

Simmel, G. (1973). A metrópole e a vida mental. In Velho, O.G. O fenômeno urbano (pp.1125). Rio de Janeiro: Zahar

Vainer, C. B. (1998). Cidades, cidadelas e a utopia do reencontro: uma reflexão sobre tolerância e urbanismo. Cadernos IPPUR, 12(1), 33-46.

Vilhena, J. (2005). Da cultura do medo à fraternidade como do laço social. In J. Vilhena, R. V. Castro, \& M. H. Zamora, A cidade e as formas de viver (pp. 19-43). Rio de Janeiro: Museu da República.

Wacquant, L. M. H. (2001). Os condenados da cidade - estudos sobre marginalidade avançada. Rio de Janeiro: Revan. 